University of Wollongong

Research Online

Faculty of Commerce - Papers (Archive)

Faculty of Business and Law

$1-1-2005$

\title{
HOGLEX Demand Systems and Welfare Policy in Major ASEAN Developing Countries: A Bayesian Analysis Using Expenditure Unit Records
}

\author{
Hikaru Hasegawa \\ University of Wollongong \\ Rebecca Valenzuela \\ University of Wollongong \\ Tran Van Hoa \\ University of Wollongong, tvheco@uow.edu.au
}

Follow this and additional works at: https://ro.uow.edu.au/commpapers

Part of the Business Commons, and the Social and Behavioral Sciences Commons

\section{Recommended Citation}

Hasegawa, Hikaru; Valenzuela, Rebecca; and Hoa, Tran Van: HOGLEX Demand Systems and Welfare Policy in Major ASEAN Developing Countries: A Bayesian Analysis Using Expenditure Unit Records 2005, 91-107.

https://ro.uow.edu.au/commpapers/1070

Research Online is the open access institutional repository for the University of Wollongong. For further information contact the UOW Library: research-pubs@uow.edu.au 


\title{
HOGLEX Demand Systems and Welfare Policy in Major ASEAN Developing Countries: A Bayesian Analysis Using Expenditure Unit Records
}

\author{
Abstract \\ the explicit and estimable HOGLEX demand system ( Tran Van Hoa, 1983, 1985 and Jerison and Jersion \\ 1984) links for the first time an important aspect of economic theory and the statisticals of Box-Cox \\ transformation analysis. \\ Keywords \\ HOGLEX, Demand, Systems, Welfare, Policy, Major, ASEAN, Developing, Countries, Bayesian, Analysis, \\ Using, Expenditure, Unit, Records \\ Disciplines \\ Business | Social and Behavioral Sciences

\section{Publication Details} \\ Tran Van Hoa, J., Hasegawa, H. \& Valenzuela, R. (2005). HOGLEX Demand Systems and Welfare Policy in \\ Major ASEAN Developing Countries: A Bayesian Analysis Using Expenditure Unit Records. In J. Tran Van \\ Hoa (Eds.), Advances in Household Economics, Consumer Behaviour and Economic Policy (pp. 91-107). \\ Hants, England: Ashgate Publishing Limited.
}




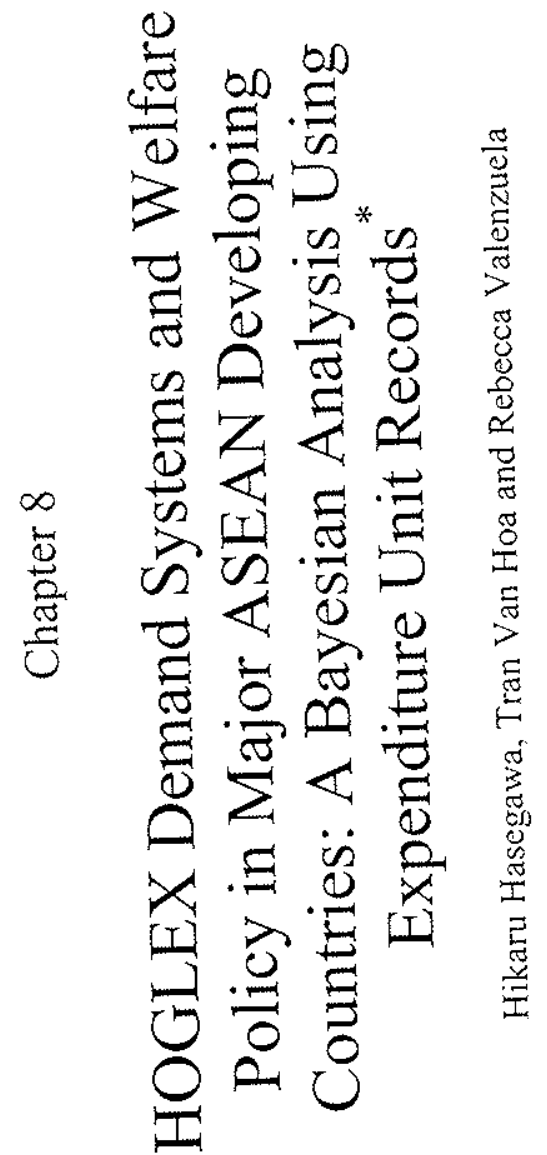

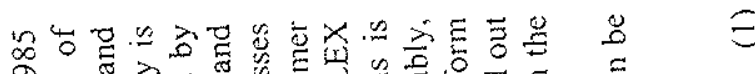

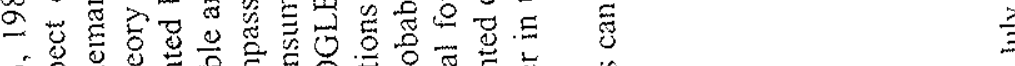

๙2.

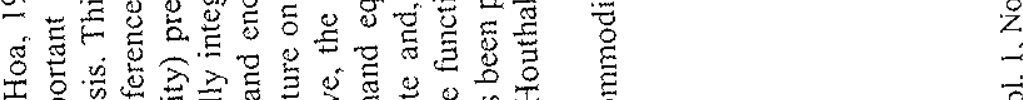

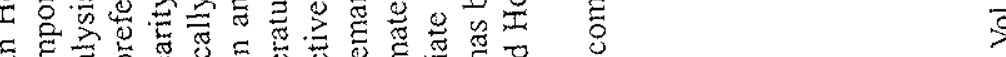

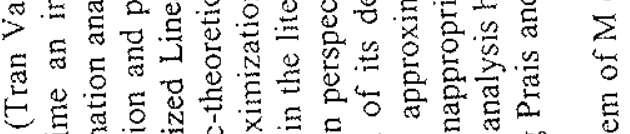

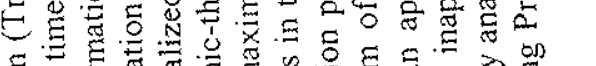

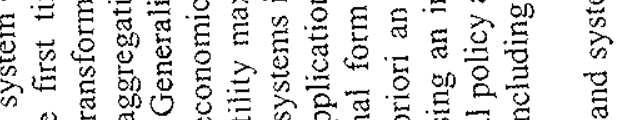

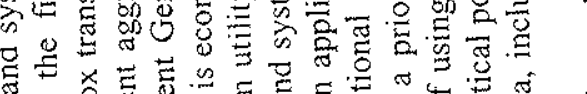

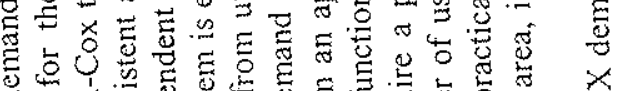

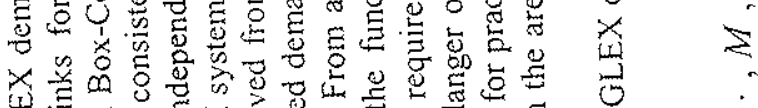

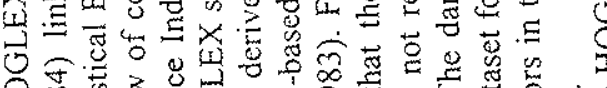

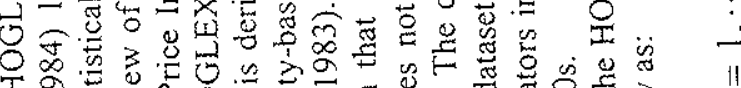

-

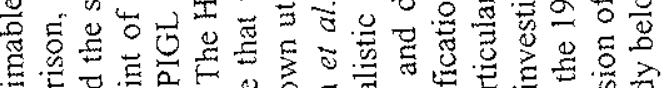

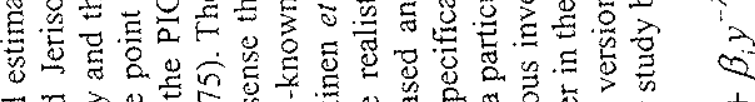

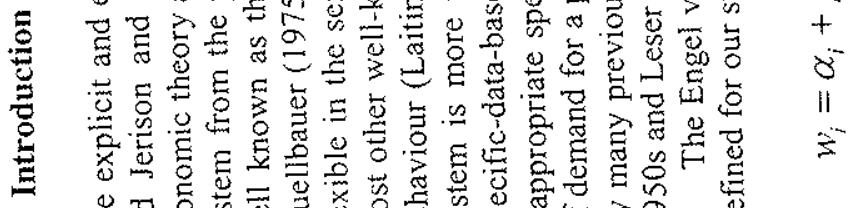




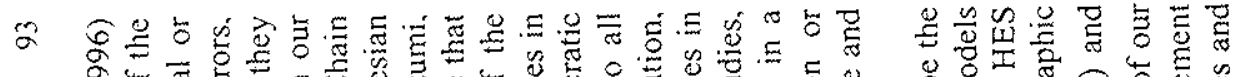

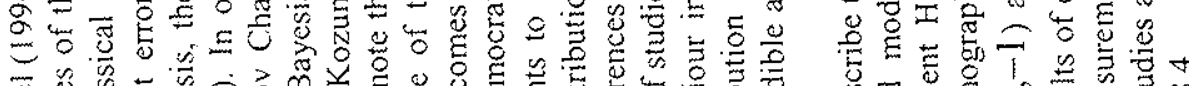

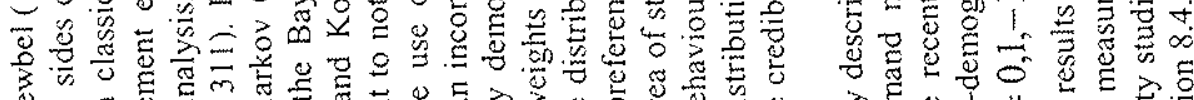

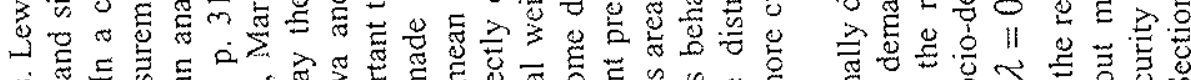

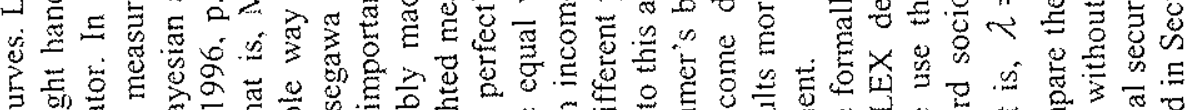

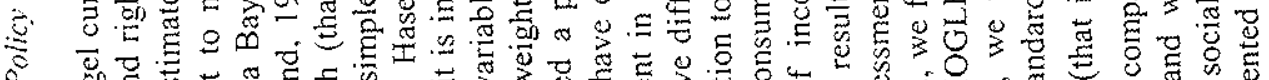

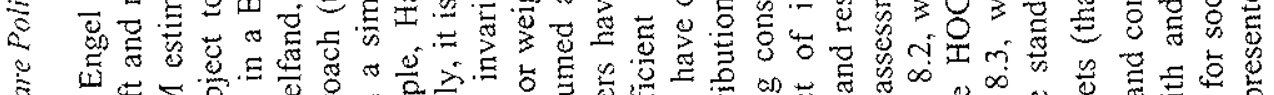
5 ब

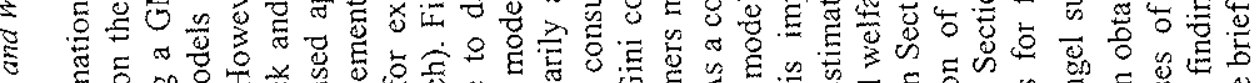

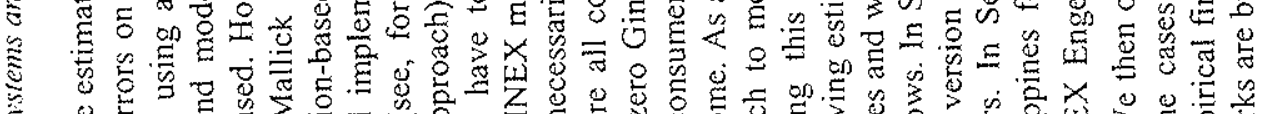

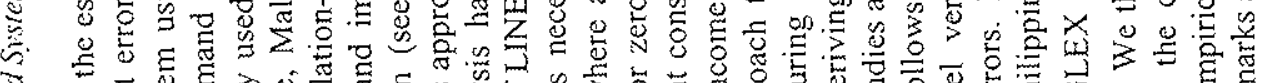

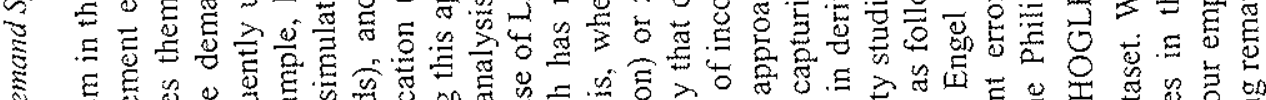

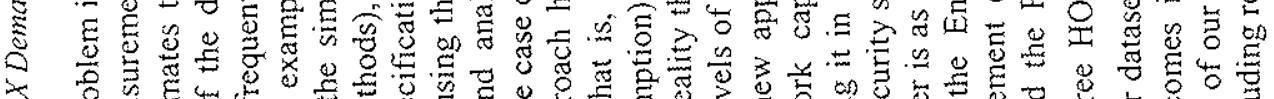

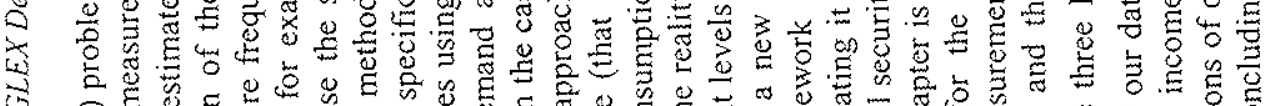

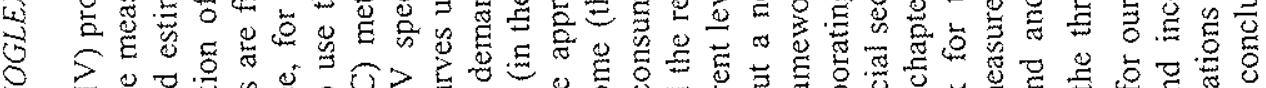

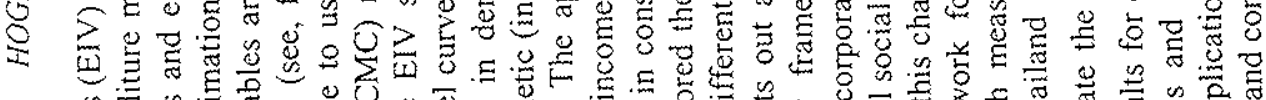
क क

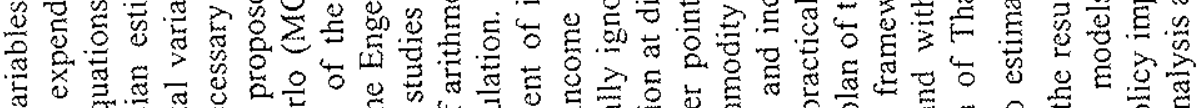

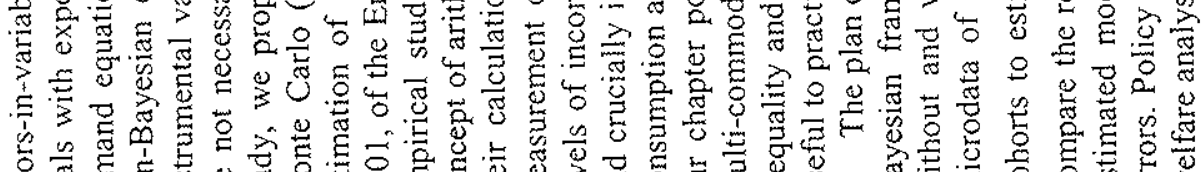

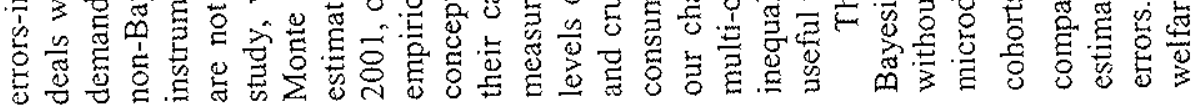
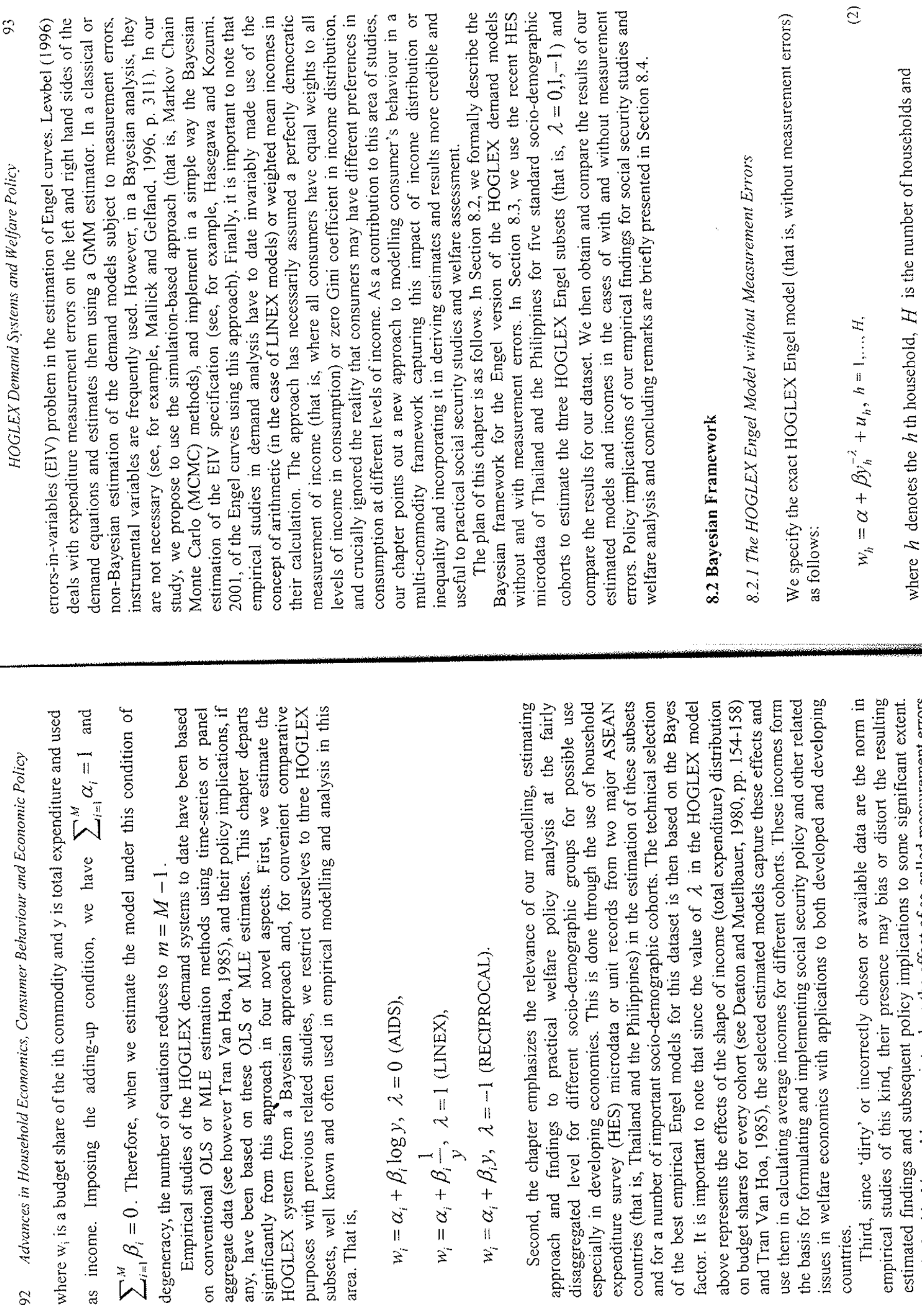

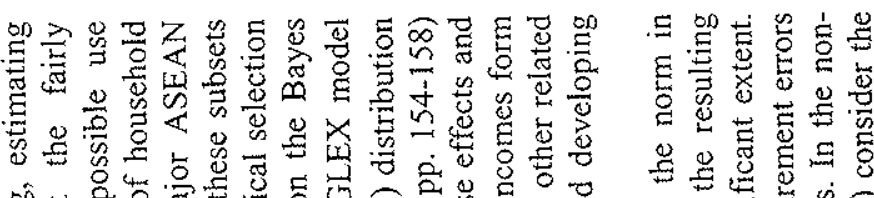

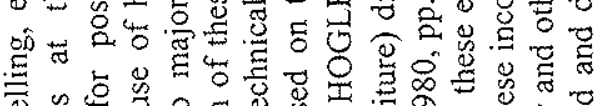

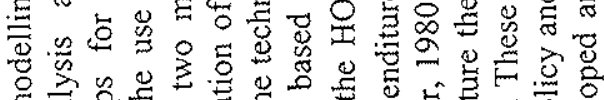

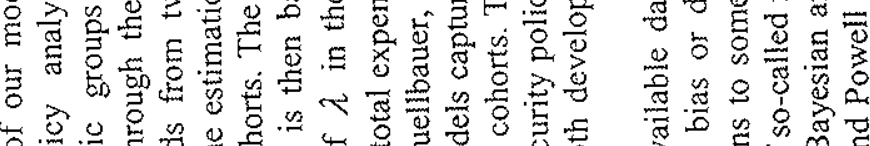

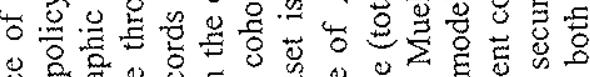

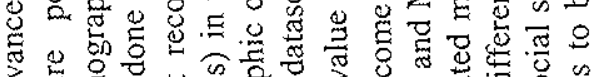
西过过

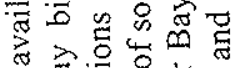

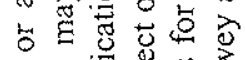

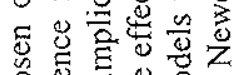

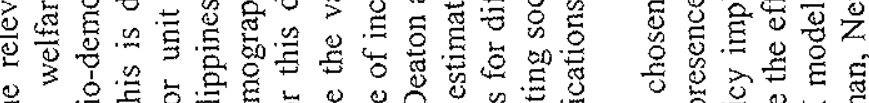

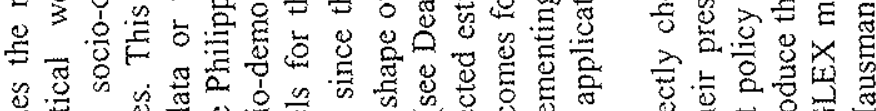

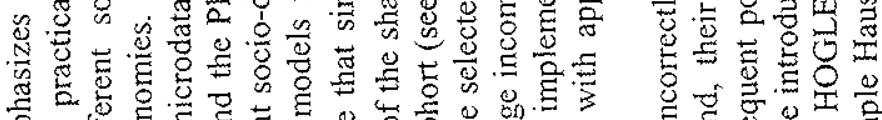

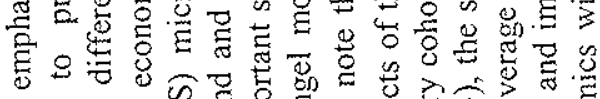

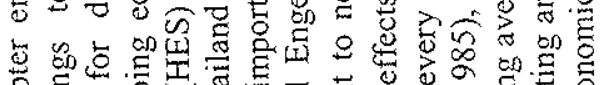

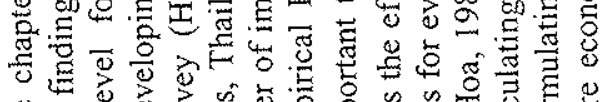

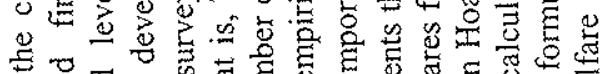

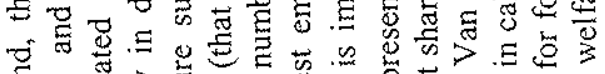

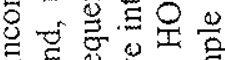

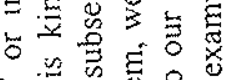

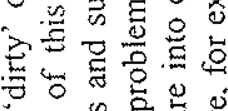

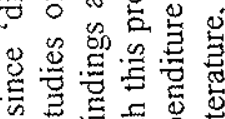

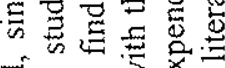

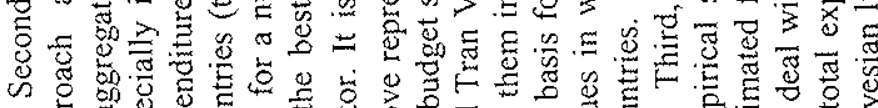

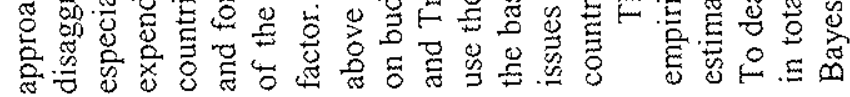



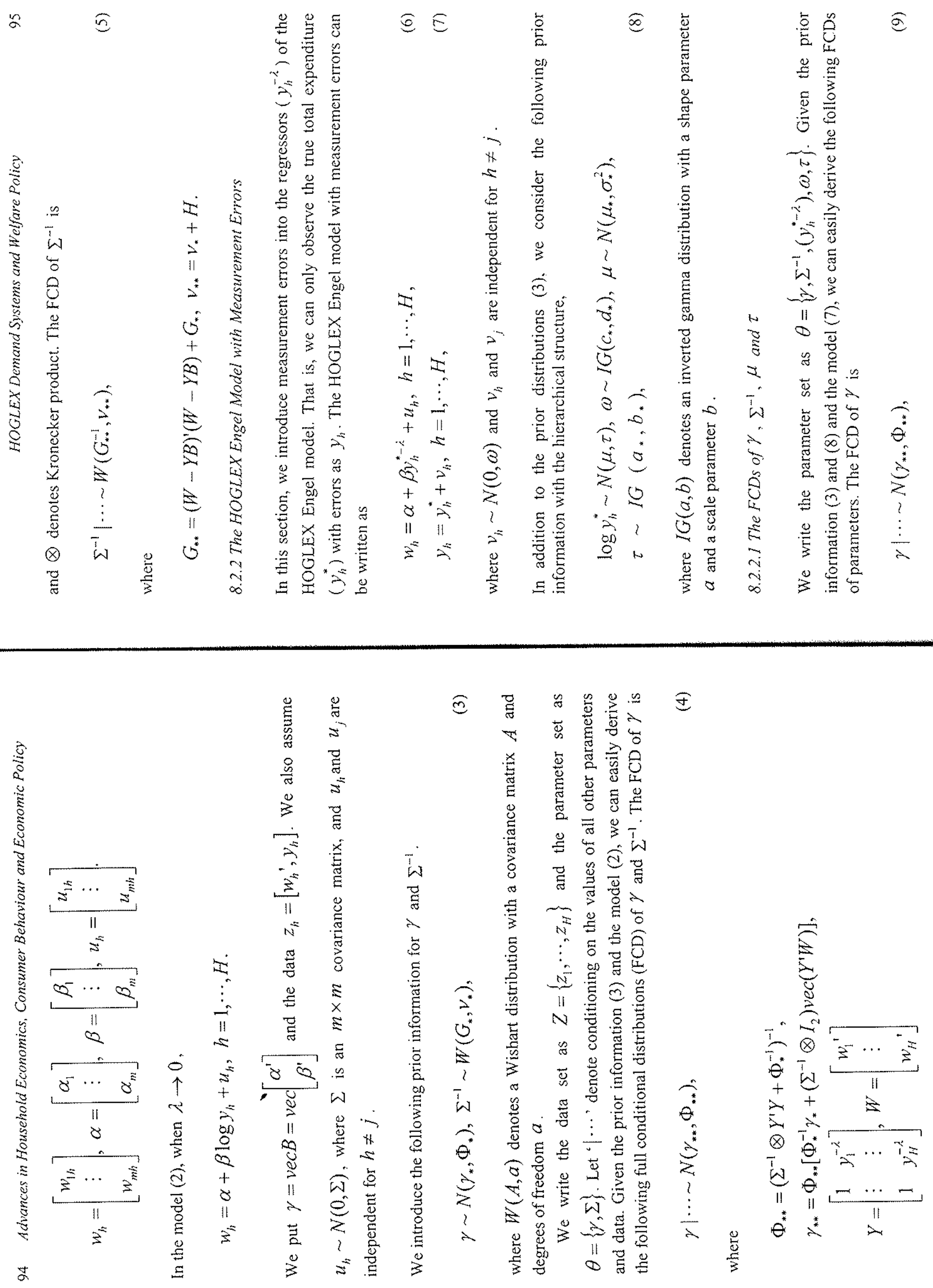


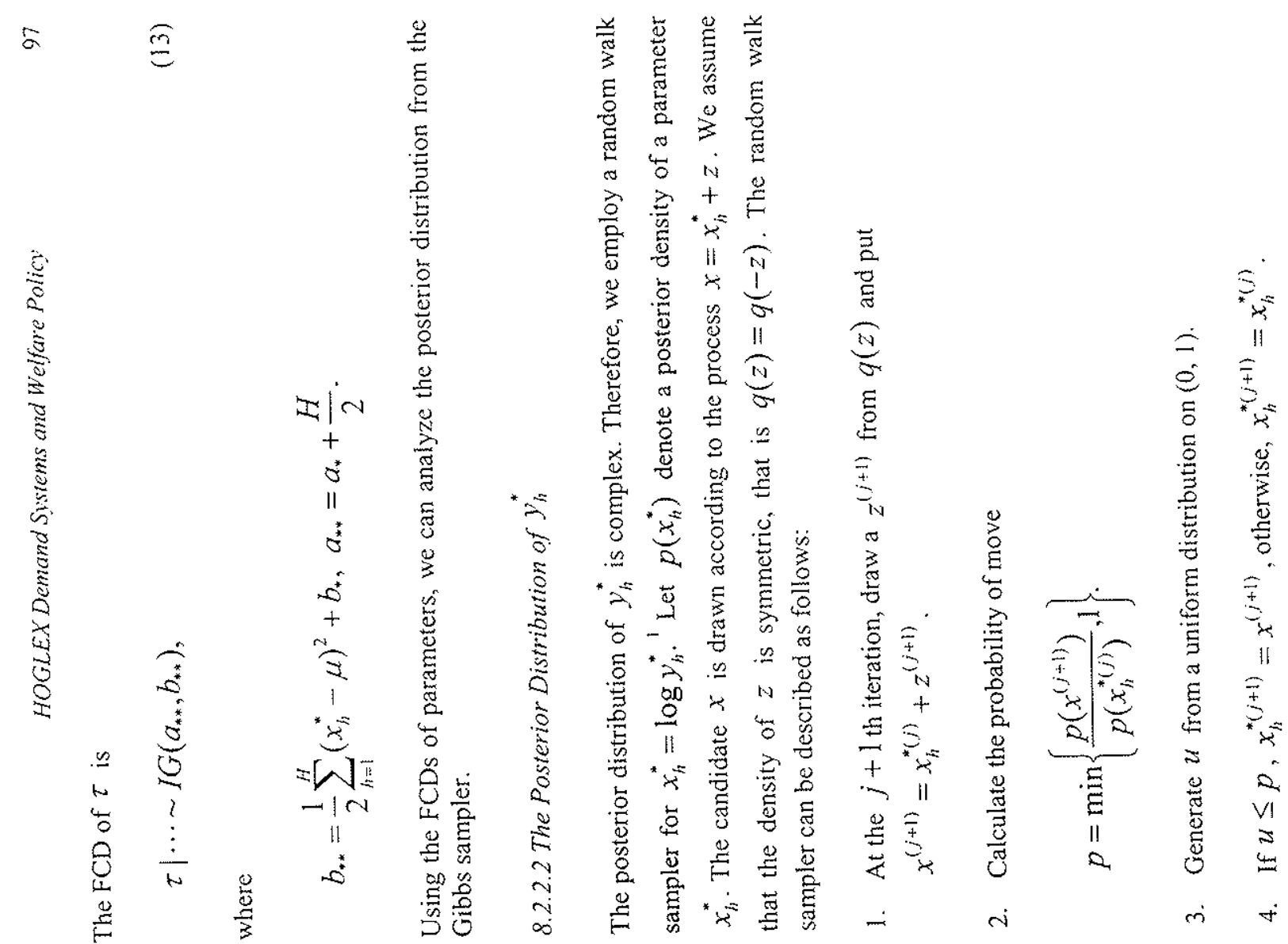



$\Xi$

త્

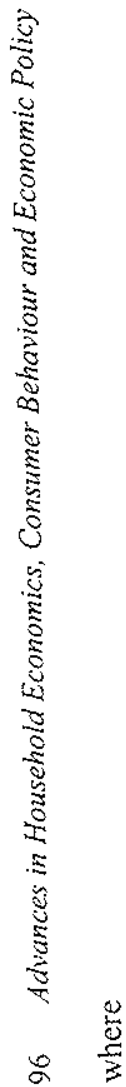

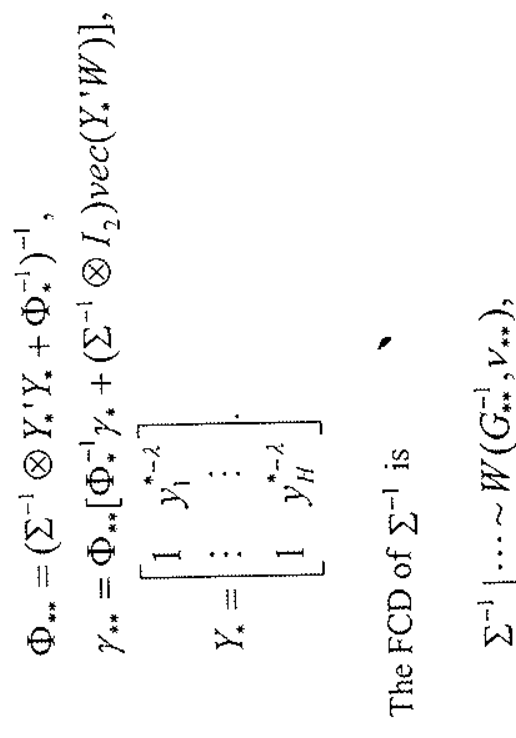

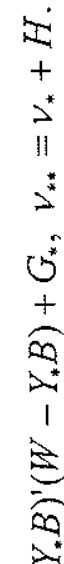

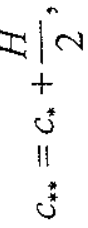

$20 *$

*

顼

$\frac{-16}{n^{*}}$<smiles>C1CCCC1</smiles>

$+0^{*}=$

茫

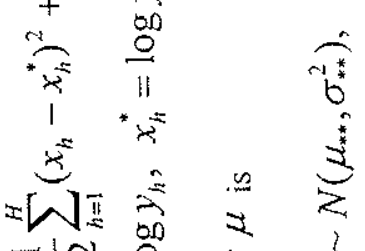

$\underbrace{+\infty}_{\substack{i 0^{*} \\-11 \\ b^{*}}}$

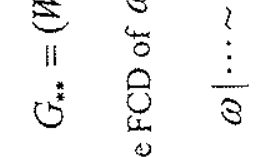

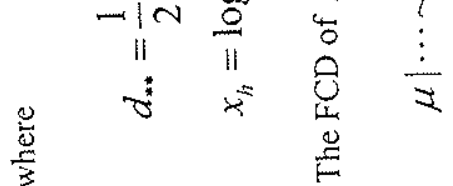




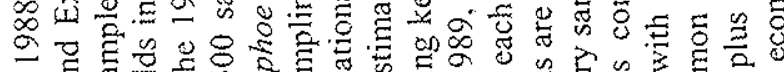

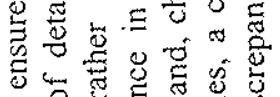

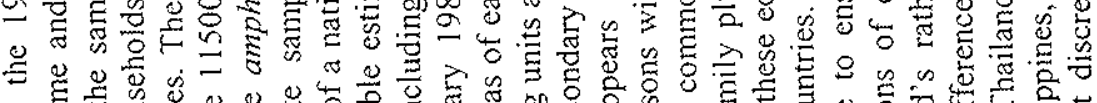

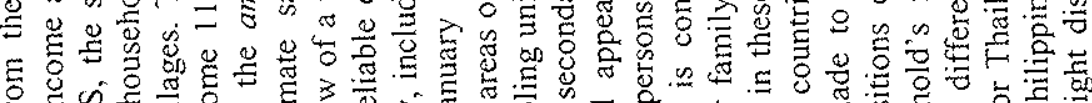

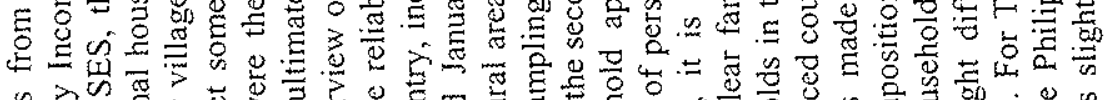

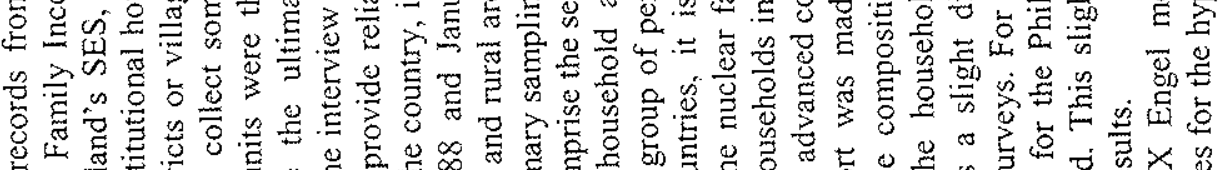

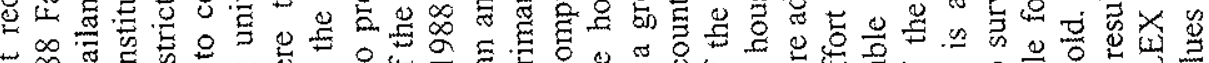

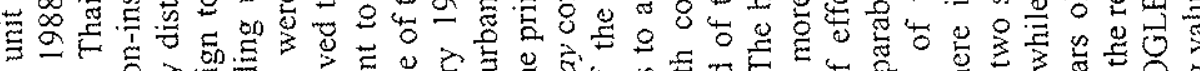

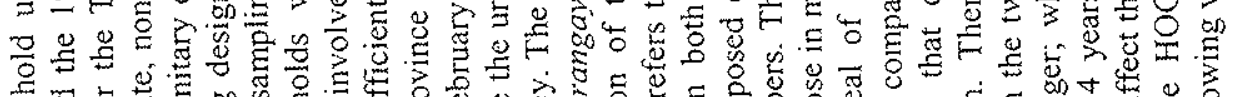

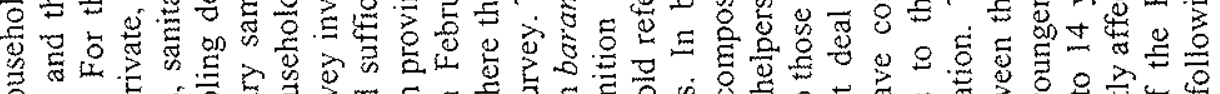

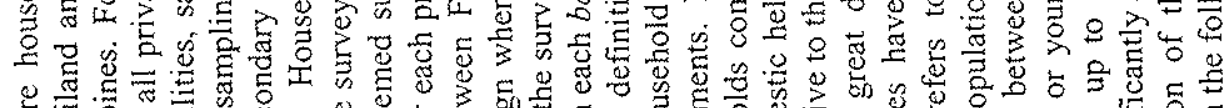

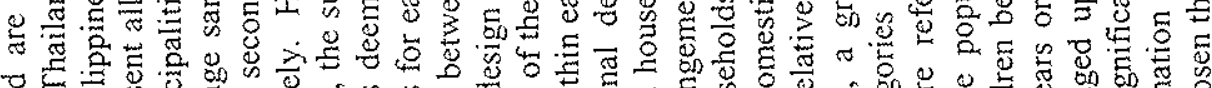

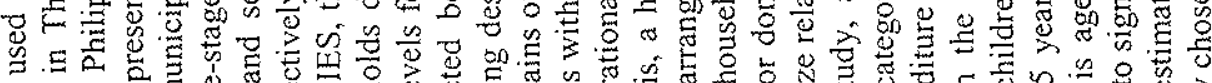

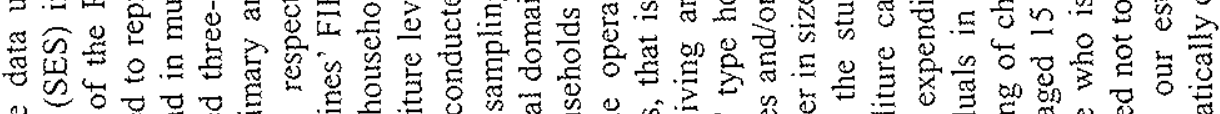

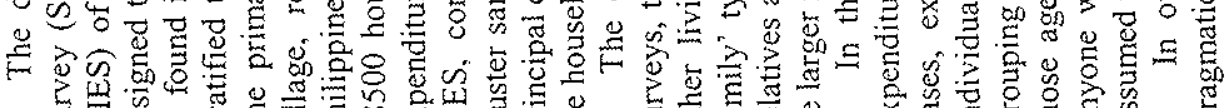

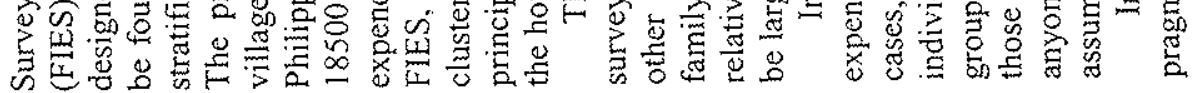

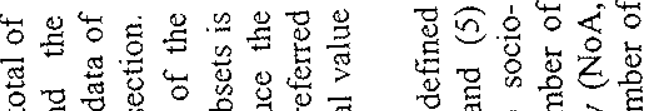

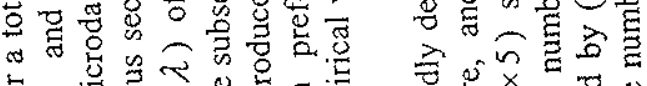

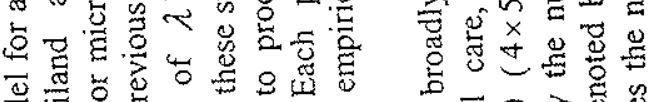

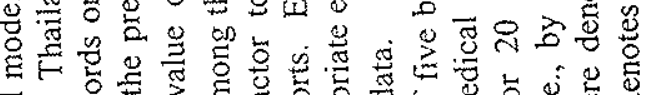

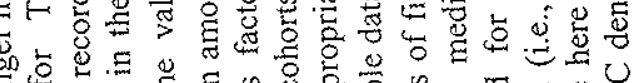

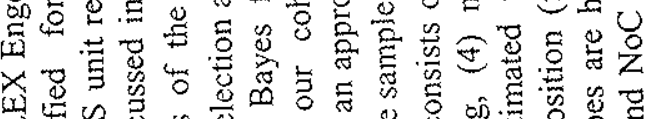

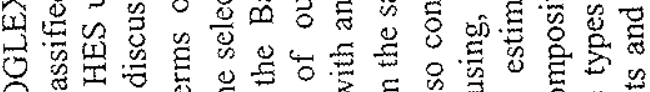

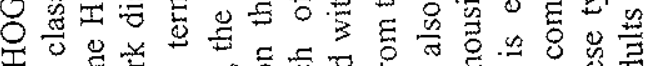

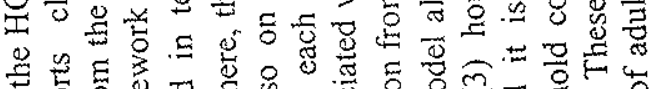

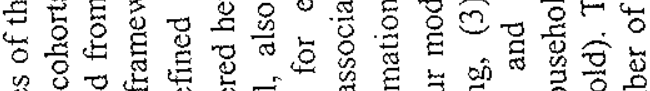

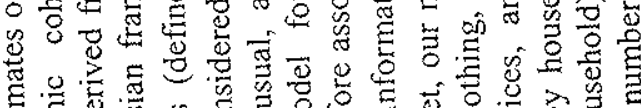

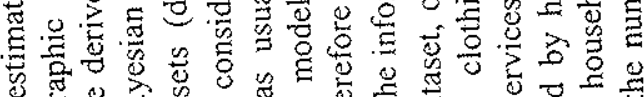

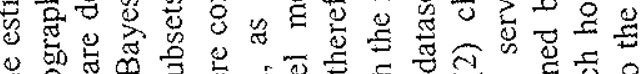

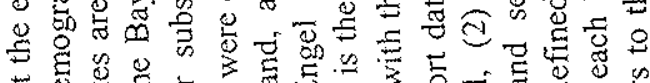

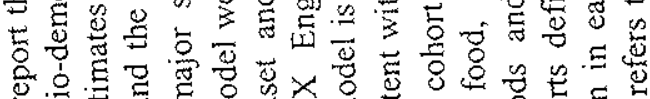

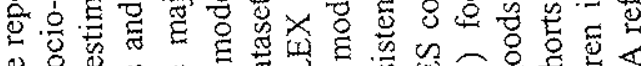

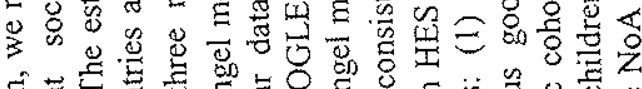

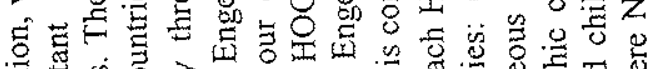

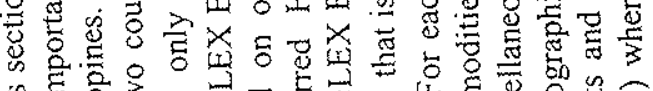

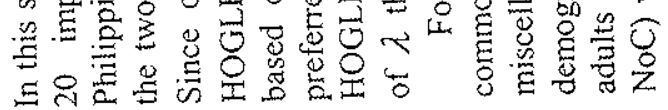



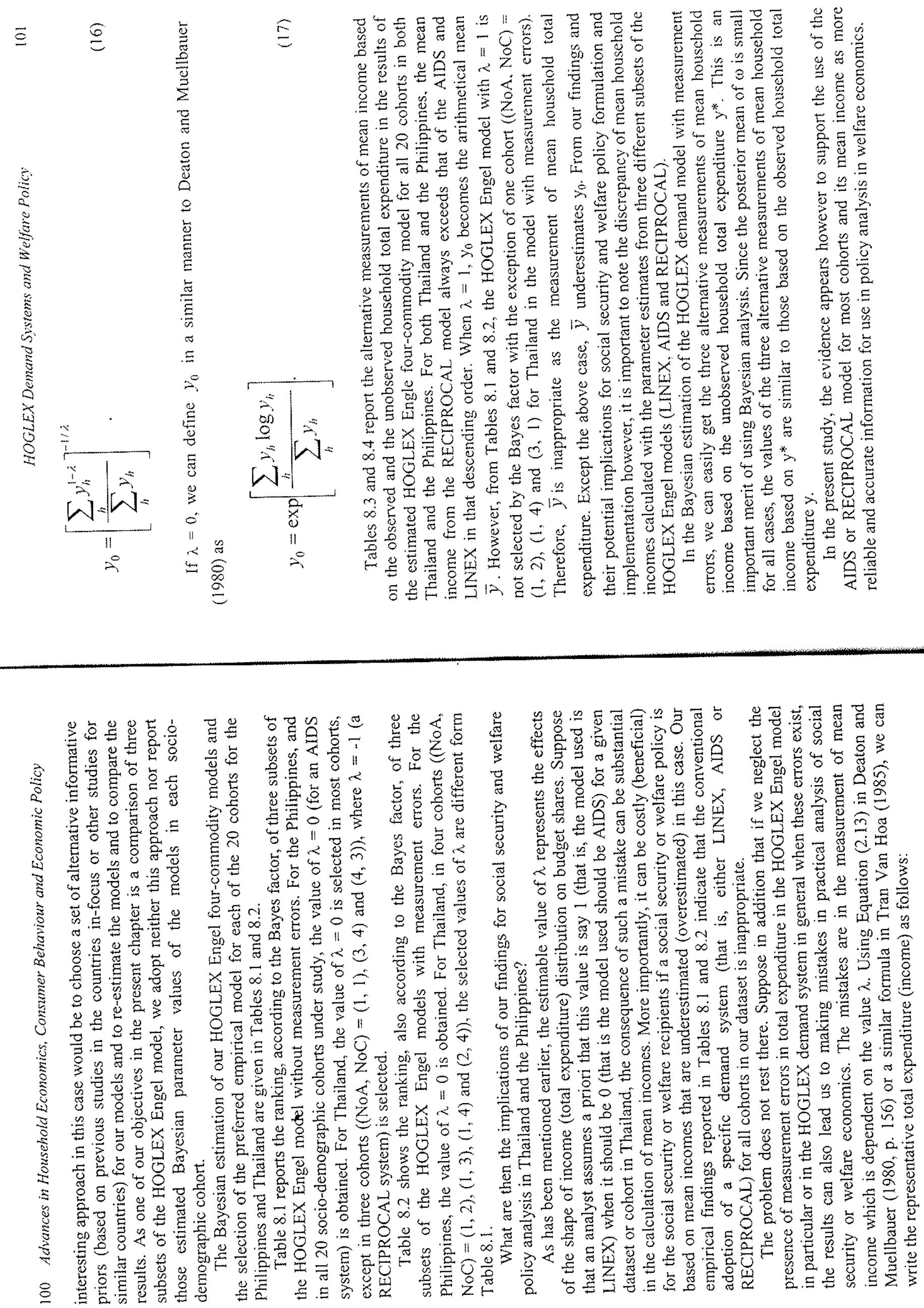


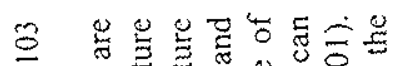

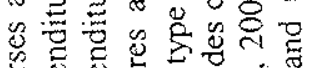

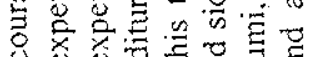

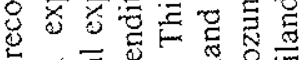

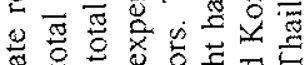
讨 可 5

方

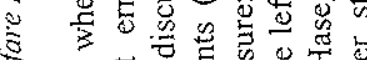
3

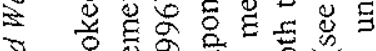
ह 안 密

공

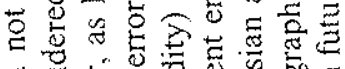

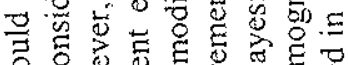

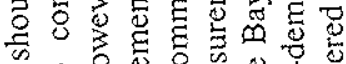

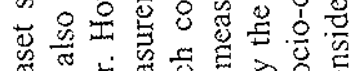

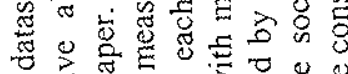
응

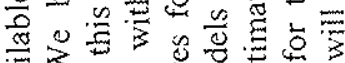

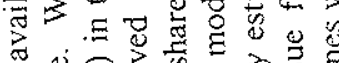

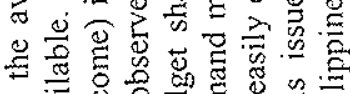

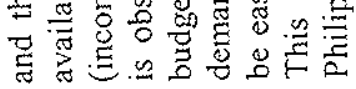

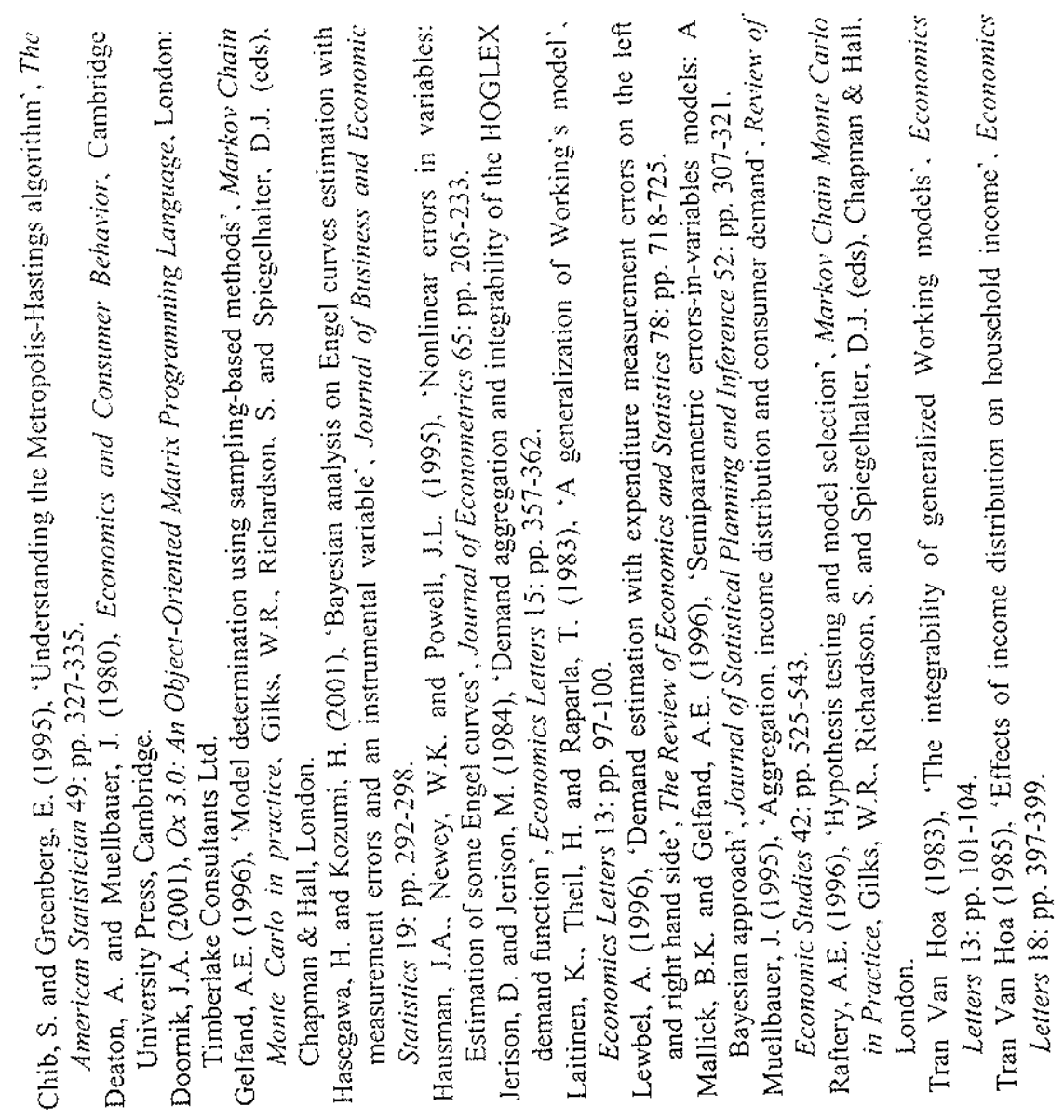

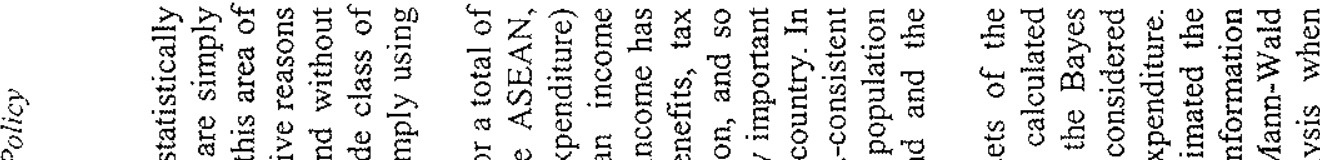

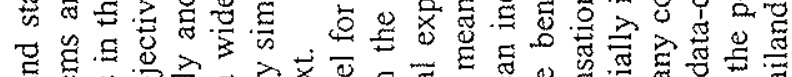

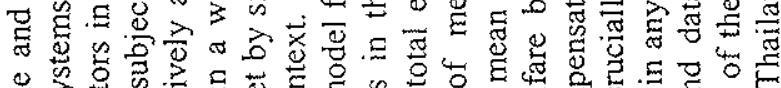

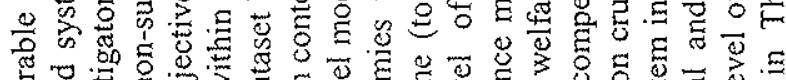

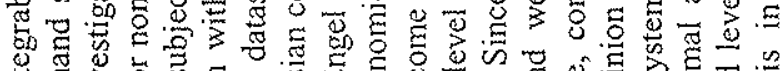

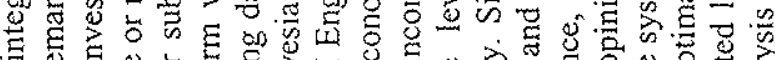

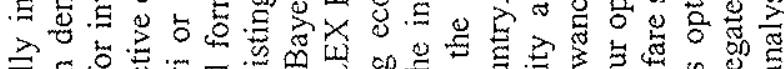

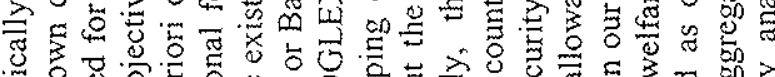

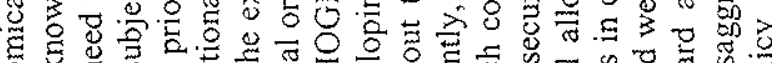

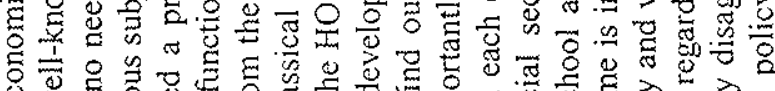

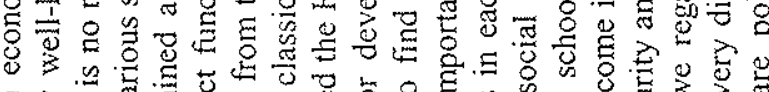

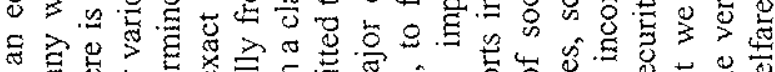

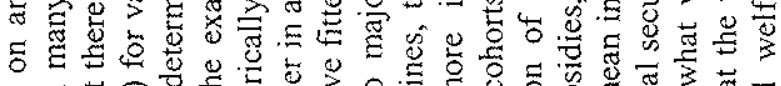

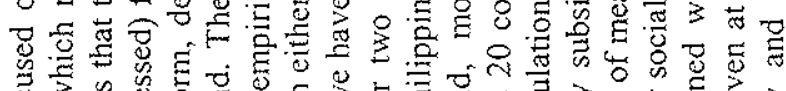

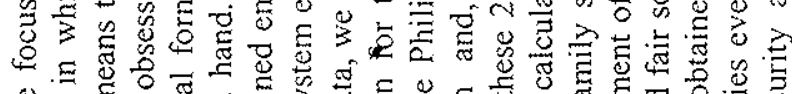

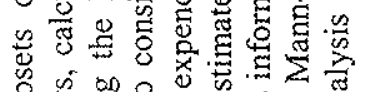

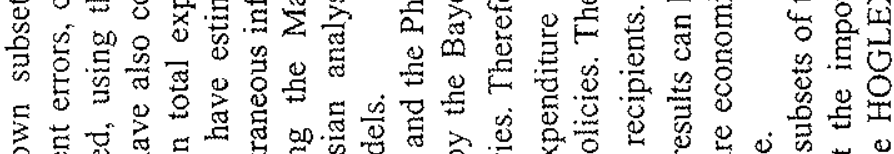

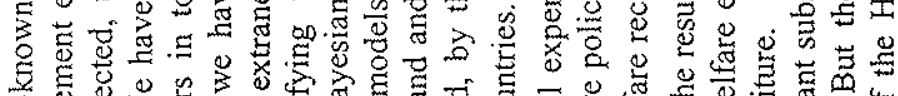

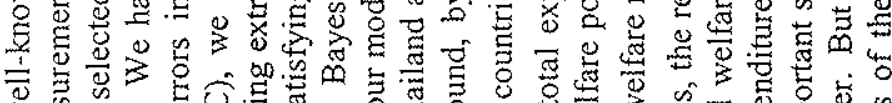

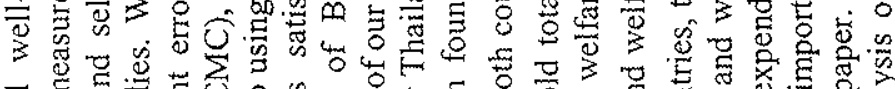

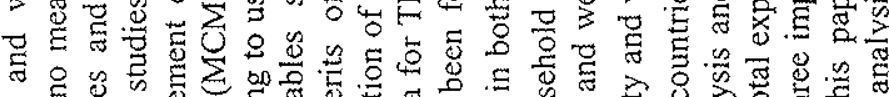

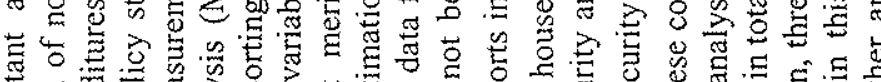

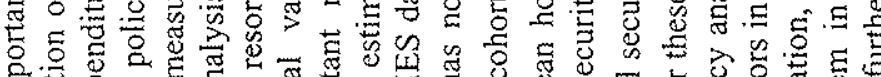

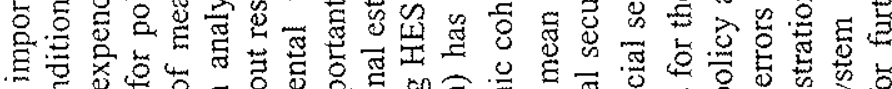
\&

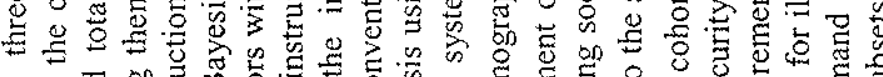

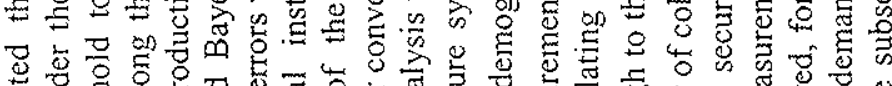

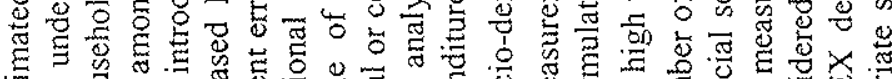

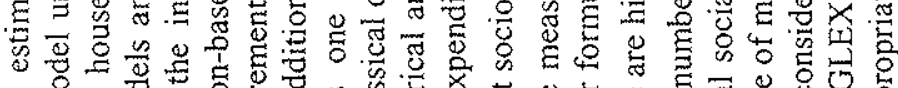

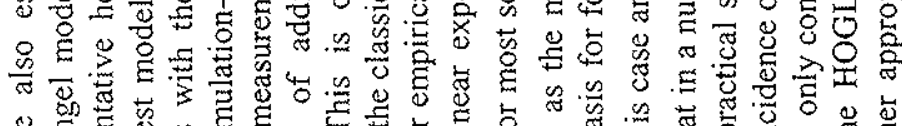

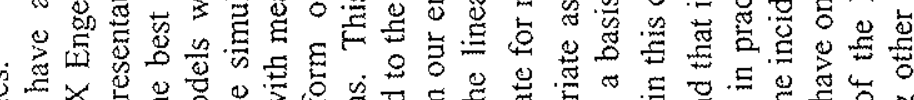
0.

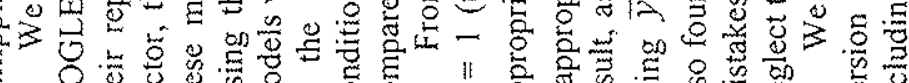
O. 


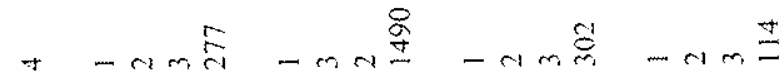

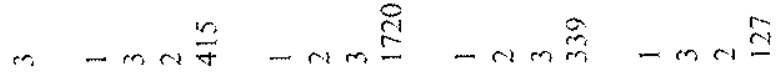

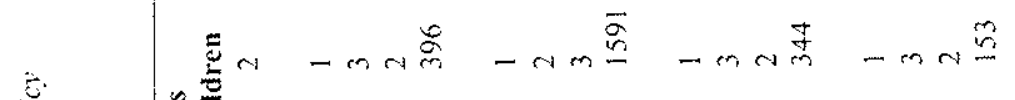

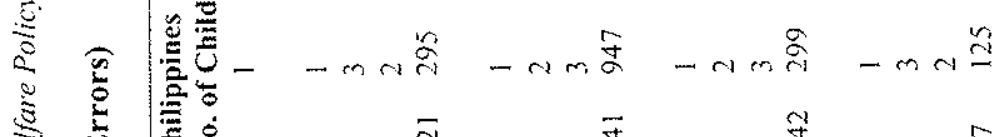

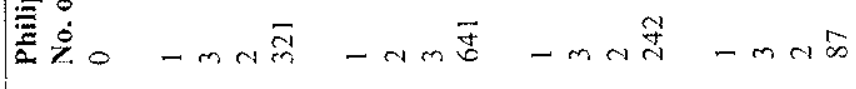

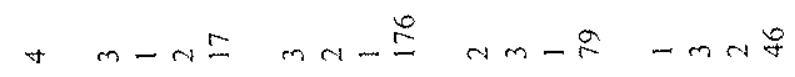

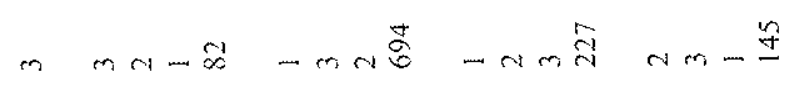

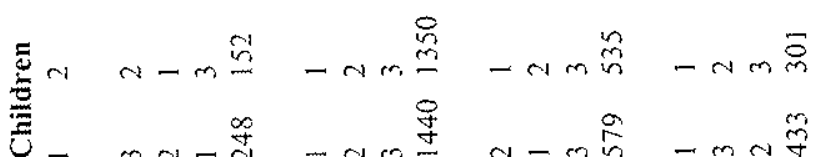

递异

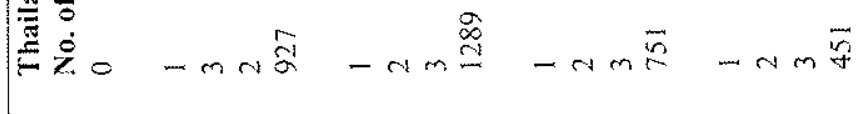

要

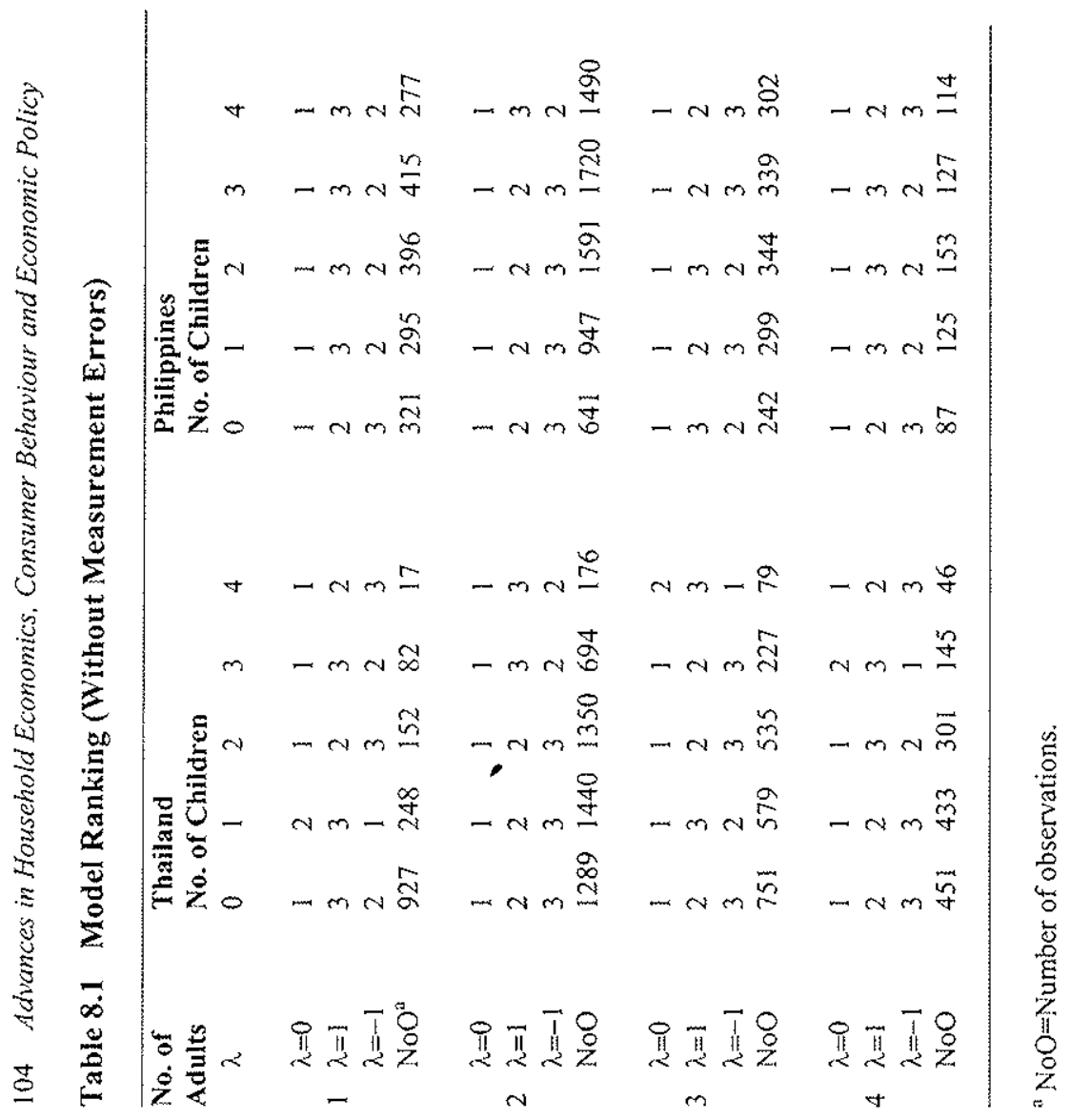




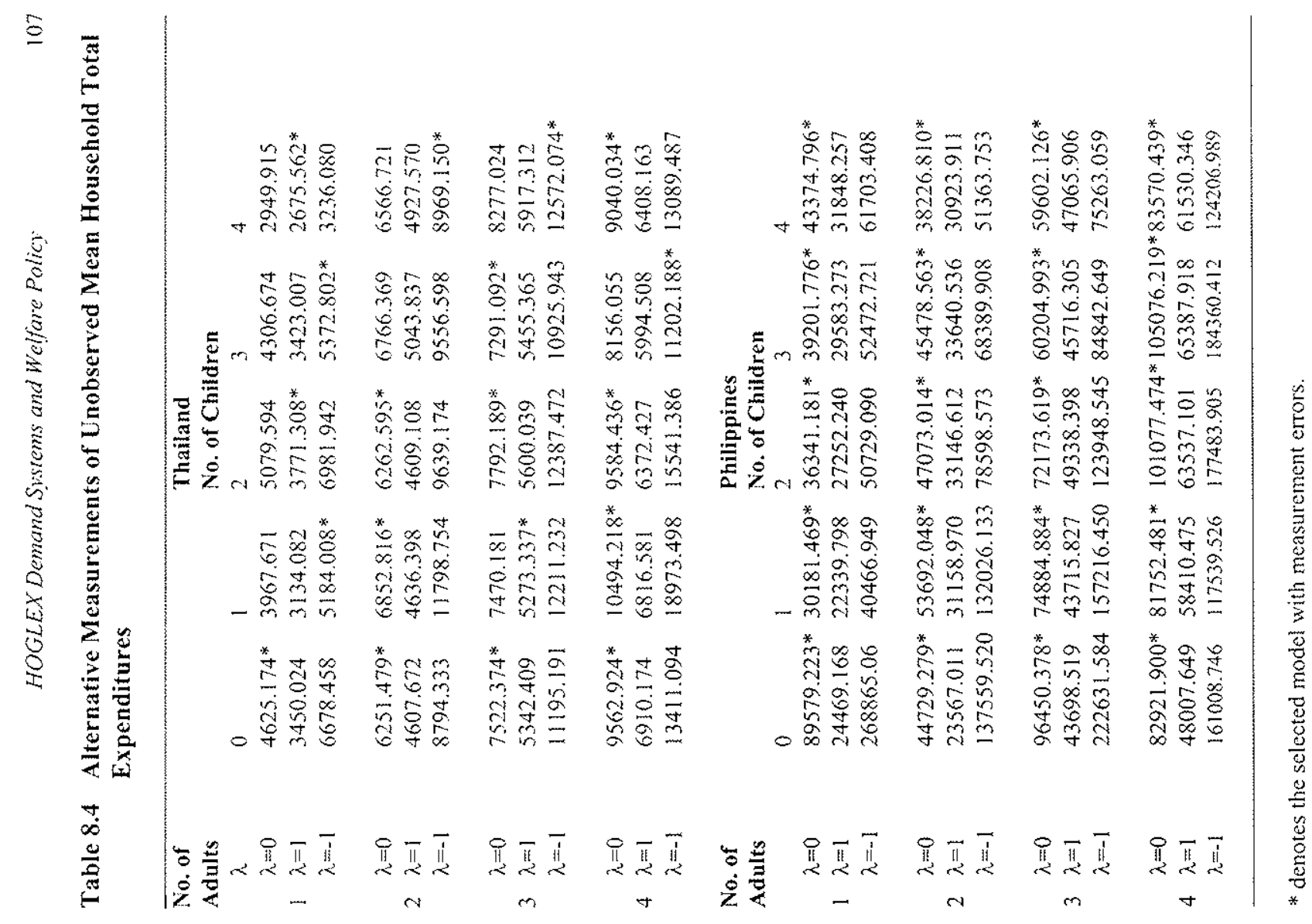

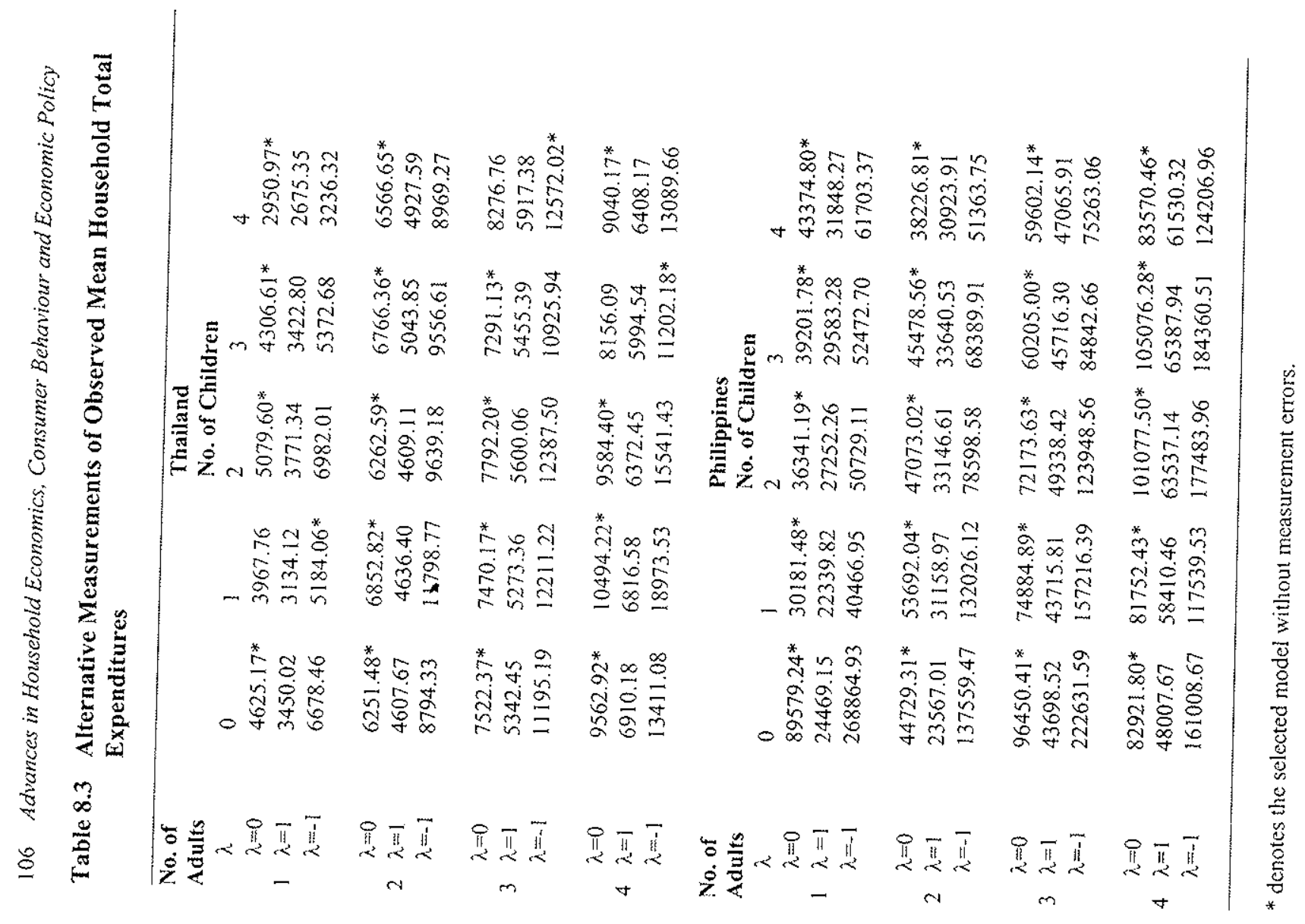

